\title{
Age-related changes of monoaminooxidases in rat cerebellar cortex
}

\author{
F.M. Tranquilli Leali, M. Artico, S. Potenza, ${ }^{*}$ C. Cavallotti \\ * Istituto di Psichiatria e Sezione di Anatomia Umana del Dipartimento di Scienze Cardiovascolari e \\ Respiratorie dell'Università “La Sapienza”, Rome, Italy
}

\section{2003, European Journal of Histochemistry}

Age-related changes of the monoaminoxidases, evaluated by enzymatic staining, quantitative analysis of images, biochemical assay and statistical analysis of data were studied in cerebellar cortex of young (3-month-old) and aged (26month-old) male Sprague-Dawley rats. The enzymatic staining shows the presence of monoamino-oxidases within the molecular and granular layers as well as within the Purkinje neurons of the cerebellum of young and aged animals. In molecular layer, and in Purkinje neurons the levels of monoaminooxidases were strongly increased in old rats. The granular layer showed, on the contrary, an age-dependent loss of enzymatic staining. These morphological findings were confirmed by biochemical results.

The possibility that age-related changes in monoaminooxidase levels may be due to impaired energy production mechanisms and/or represent the consequence of reduced energetic needs is discussed.

Key words: cerebellar cortex, monoamino-oxidases, MA0-A, MAO-B, quantitative analysis of images, age-related changes.

Correspondence: Carlo Cavallotti, M.D., Dipartimento di Scienze Cardiovascolari e Respiratorie, Università of Roma “La Sapienza”, via A. Borelli 50, 00161 Rome, Italy. Phone: international +39.06.4958291. Fax: international +39.06.4957669. E-mail: cavallotti@uniroma1.it

Paper accepted on October 5, 2002

European Journal of Histochemistry 2003; vol. 47 issue 1 [Jan-Mar]:81-86
$T$ he monoaminooxidases (MAOs) are intracellular enzymes linked to the mitochondrial membranes of nervous cells (Brus 1975, Saura et al. 1994a, 1994b). These enzymes were intensively studied about 30 years ago in the central nervous system (CNS) (Studer et al. 1964, Prange et al. 1967, Blaschko 1974, Tipton et al. 1976). MAOs exsist in two molecular forms: MAO-A and MAO-B; these two forms are different both in specific substrates (Fowler et al. 1981, Tipton et al. 1983) and inhibitor-sensitivity. MA0-A is sensitive to clorgyline (Johnston 1968) and MAO-B to deprenyl (Knoll and Magyar 1972). A third form of MAO was identified in some mammal tissues, the so called MAO-C, which is not sensitive either to clorgyline or deprenyl. This third MAO form utilizes benzylamine as substrate and is sensitive to the inhibitor semicarbazide (Cao Danh et al. 1984). MAOs contribute to the regulation of neuronal activity by maintaining an unchanged level of catecholaminergic neurotransmitters. These enzymes show a sharp age-dependent increase, above-all in the rat brain (Lai et al. 1978), as demonstrated by biochemical studies (Prange et al. 1967, Fowler et al. 1980). Recently, MAOs come into fashion again due to the important role that they play in neurodegenerative diseases (Hoffman et al. 1997, Moody et al. 1997, Esiri et al. 1999, Thomas et al. 1998, 1999, 2000a, 2000b).

Despite all these studies, no results regarding the topographical localization of MAO in the cerebellar cortex are available, except for some studies that have demonstrated an increase of MAO in old rats (Studer et. al. 1964, Prange et al. 1967) by means of histochemical techniques. In our opinion, these data have some limitations: 1) the authors consider 14 month-old rats as old; while in literature a rat is old after 24 month of age; 2 ) the same authors are not interested in the different localization of the MAO in the various types of cells of the cerebellar cortex. 
For these reasons age-related changes of MAOs in the rat cerebellar cortex were studied in this work, correlating morphological and biochemical data and performing a quantitative evaluation of the enzymatic staining. Moreover, total MAO and the two subgroups: MAO-A and MAO-B were studied by means of morphological and biochemical techniques.

\section{Materials and Methods}

In this experiment 8 Sprague-Dawley rats 3 month-old (young) and 8 rats 24 months-old (old) were used. The animals were kept at a constant temperature $\left(22^{\circ} \mathrm{C}\right)$ with a $10-14$ dark-light rhythm, with free access to water and food. The maximum life-span in our colony was $26 / 28$ months. Each animal was weighed every day and the weights were recorded. The animals were treated according to the Convention of Helsinki on the utilization of animals in biomedical research. They were sacrificed by means of terminal anaesthesia (50 $\mathrm{mg} / \mathrm{kg}$ of endoperitoneal Nembutal).

The skull cavity was opened and the cerebellum was identified, removed, washed, weighed and put in cold phosphate buffer-solution.

Samples of the cerebellar cortex were drawn, under an operative microscope, weighed and soaked in cold isopentane, frozen in liquid nitrogen, cut serially at the microtome freezer into 10-15micron slices and treated for the enzymatic staining of the MAO. Other samples of the same cerebellar cortex were dissected, under operative microscope, in three laminar layers, each layer containing only molecular, Purkinje, and/or granular cells. Each of these three layers was homogenized in cold phosphate buffer-solution 1:10 weight/volume and used for biochemical assay (proteins, enzymes).

Staining of the MAO was performed according to the method suggested by Uchida and Koelle (1984). This method is based on an initial pre-incubation of the sections in a $30 \% \mathrm{Na}_{2} \mathrm{SO}_{4}$ solution for 1 hour at $37^{\circ} \mathrm{C}$. A second pre-incubation was made in $0.05 \mathrm{M}$ phosphate buffer-solution ( $\mathrm{pH} 7.6)$ containing sucrose $(8 \%)$ either with or without $10^{-7}$ moles of 1) clorgyline as MAO-A specific inhibitor (Johnston 1968) or 2) deprenyl as MAO-B specific inhibitor (Knoll and Magyar 1972). At the end of the second incubation, the sections were washed in phosphate buffer- solution and stained by incubating them in a solution containing phosphate buffer $(0.05 \mathrm{M} \mathrm{pH} 7.6)$, nitroblue tetrazolium (saturated solution, used as dye), sucrose ( $8 \%)$ and tryptamine ( $1 \mathrm{mmol} / \mathrm{L}$, used as a substrate and starter of the reaction) at $37^{\circ} \mathrm{C}$ for $1-2 \mathrm{~h}$.

The sections were then washed in $\mathrm{H}_{2} \mathrm{O}$, fixed by means of a $10 \%$ formalin solution, dehydrated and embedded in Entellan (Merck). The specificity of the reaction was evaluated by incubating some control sections in a medium either without substrate (tryptamine) or without dye (nitroblue tetrazolium). In both cases the reaction was negative. On the contrary, the reaction was considered to be positive when nitroblue tetrazolium precipitates were present. In this case the granules appear blue on slides and black on black-and-white photographs.

The quantitative analysis of images (QAI) was performed both on slides and/or related photograph, at the same magnification and the same lighting, using a Quantimet 500 Leica $^{\circledR}$ apparatus for morphometrical and quantitative analysis, as reported with further details in the Handbook of Methods (1997). QAI makes it possible to obtain data for many morphological parameters (e.g.: number of cells, surface of a structure, intensity of a reaction, specific parameters, specific surfaces, white or black or grey intensity etc.). The value 0 , indicates a negative reaction and may be obtained, for example, by omitting the substrate in the incubation medium or the specific dye but also by adding an excess of the specific reaction-inhibitor. The value 100 indicates the maximum intensity of the reaction present in the samples with the highest staining. The final values are expressed in Conventional Units (CU士SEM) and are directly provided by the instruments. The exact definition of $\mathrm{CU}$ is reported in the Handbook of Methods (1997).

The results obtained by using QAI are not absolute but only relative and have many limitations; most parameters contained in the software are variable and are chosen depending on the personal preferences of each researcher. In other words, the parameters are not objective but subjective. For these reasons they are approximate and the final results can only be utilized for comparative purposes, i.e. in comparison to other results obtained in the same experimental conditions. In order to make the results as objective as possible, it is necessary to adopt many precautions: measurements must be repeated at least three times by different persons, using different instruments and with double-blind-method. The samples must be marked only by a number or a letter and must be identified 
only when all the experimental procedures have been performed. The final results must then be statistically analysed to estimate the significance index.

Amount of protein: in all our experiments, samples of each layer of cerebellar cortex were weighed and homogenised into an ice-cold homogenisation buffer. Tissue protein concentrations were determined following the method described by Lowry et al. (1951) using bovine serum albumin (BSA) as standard and Folin phenol as reagent.

Enzymatic assays: individual subtypes of MAOs were assayed on Zeiss Model PMQ II Spectrophotometer by the rate of change of concentrations of NAD (nicotinamine adenine dinucleotides) or NADP, as shown by extinction measurements at $340 \mathrm{~mm}$ at room temperature $\left(19^{\circ} \mathrm{C}\right)$. Results were recorded on a Varian model G-42A graphic recorder. Suitable controls were performed, routinely in parallel with each determination. The blank contained the basic medium plus the sample but substrate or NAD were omitted or an excess of inhibitors was added. The values of the blank (endogenous values of extinction) were subtracted from each sample. The reaction mixture was buffered with $0.5 \mathrm{M}$ potassium phosphate buffer $(\mathrm{pH} \mathrm{7.4)}$ until final volume of $2.7 \mathrm{~mL}$ in a $1 \mathrm{~cm}$ quartz cuvette (Beisenherz 1955). The MAO-A (E.C. 1. 4. 3. 4.) was assessed with 5-hydroxytriptamine as substrate $(1 \mathrm{mmol} / \mathrm{L})$, while the subtype $B$ of the same enzyme was assessed with benzylamine ( $1 \mathrm{mmol} / \mathrm{L}$ ) as substrate. Final values were expressed as nmol/mg protein, calculated on the bases of the extinction coefficient and of protein content (Owen et al. 1987).

The statistical methods used in these experiments must be interpreted as an accurate description of data rather than a manipulation and an interference. Previous calculations were made using basic statistical methods, i.e. by calculating the arithmetic mean, the extreme values, the variance, the standard deviation, the standard error and the correlation coefficient as indicated by Serio (1986). The relationships between the single variable were studied by means of the correlation matrix identifying any linear or non-linear correlations. To obtain the significance or probability index the single relevant differences are compared with the corresponding values of homogenous groups. The coefficient of correlation was significant if $p<0.001$ but not when $p>0.05$. These data were calculated
Table 1. MAOs staining (without inhibitors) in cerebellar cortex of young and old rats. Quantitative analysis of images.

\begin{tabular}{lcc}
\hline \hline Stained structures & Young rats $n=8$ & Old rats $n=8$ \\
\hline & & \\
& & \\
Purkinje cells (P) & $65.9 \pm 2.4$ & $74.1 \pm 2.7^{*}$ \\
Granular cells (G) & $51.3 \pm 1.9$ & $46.4 \pm 2.5^{*}$ \\
Molecular cells (M) & $66.4 \pm 2.2$ & $87.6 \pm 3.1^{*}$
\end{tabular}

Results are expressed in C.U. (see above) \pm S.E.M.; * $p<0.001$ old versus young. $n=$ number of animals

Table 2. MAOs activity (without inhibitors) in cerebellar cortex of young and old rats. Enzymatic assay

\begin{tabular}{lcc}
\hline \hline Dissected structures & Young rats $n=8$ & Old rats $n=8$ \\
\hline Purkinje cells (P) & $62.3 \pm 2.3$ & $69.5 \pm 2.5^{*}$ \\
Granular cells (G) & $45.6 \pm 1.7$ & $41.6 \pm 2.7^{*}$ \\
Molecular cells (M) & $63.5 \pm 2.6$ & $74.4 \pm 2.8^{*}$ \\
\end{tabular}

Results are expressed as $\mathrm{nmol} / \mathrm{mg}$ protein \pm SEM. ${ }^{*} P<0.001$ old versus young n=number of animals

Table 3. MAO-B activity (with inhibitor clorgyline) in cerebellar cortex of young and old rats. Enzymatic assay

\begin{tabular}{lcc}
\hline \hline & & \\
Dissected structures & Young rats $n=8$ & Old rats $n=8$ \\
\hline Purkinje cells (P) & $49.3 \pm 2.1$ & $56.4 \pm 2.6^{*}$ \\
Granular cells (G) & $29.4 \pm 1.4$ & $25.3 \pm 2.3^{*}$ \\
Molecular cells (M) & $44.2 \pm 2.4$ & $54.6 \pm 2.5^{*}$
\end{tabular}

Results are expressed as $n m o l / m g$ protein $\pm S E M ; * P<0.001$ old versus young $n=n u m$ ber of animals. MAO-B is about $70 \%$ of MAOs.

according to the instructions provided by Castino and Roletto (1992).

\section{Results}

Our experimental findings are illustrated in Figures 1-6 and in Tables 1-3.

The microphotographs 1-2 must be compared in order to point out the difference between the MAO activities in young (Figure 1 ) and old (Figure 2) rats. The enzymatic staining (total MAO = MAO-A plus MAO-B plus MAO-C) is present in Purkinje cells $(P)$, in the cells of the molecular layer $(M)$ and also in the granular layer $(G)$. In the old rats there is an increase of enzymatic staining that does not, however, concern all the structures of the cerebellar cortex. In fact, the cells of the granular layer show a loss of enzymatic staining, on the contrary, an increase of the specific staining of the cells of the molecular layer and the Purkinje layer of the old rat cerebellar cortex compared to young rats is 


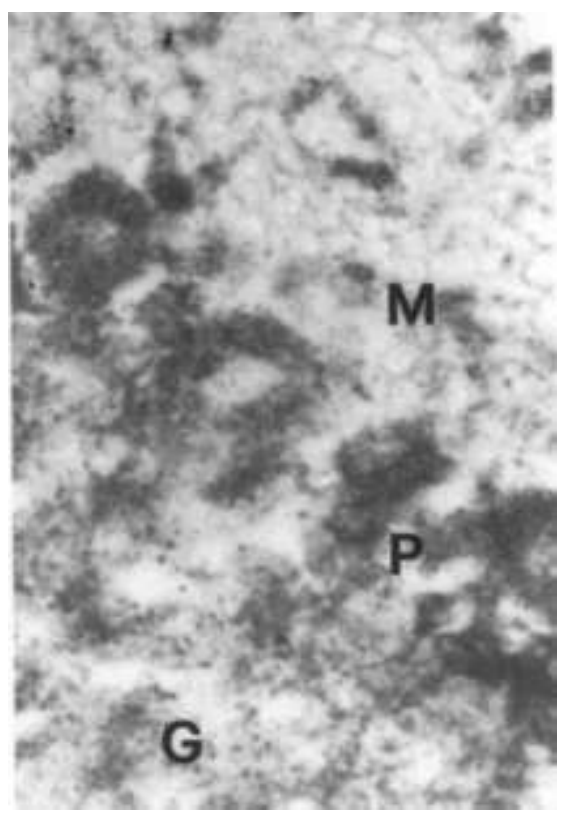

Figure 1. MAO activity in a young rat cere(magnification 250). A positive MAO reac- (magnification 250). There is a more tion (including MAO-A, MAO-B and MAO-C) intense positive MAO reaction, but the is noticeable in the cells of the three layers increase of staining do not concern the of the cerebellar cortex. $M=$ molecular cells of the granular layer. $M=$ molecular cells; $P=$ Purkinje cells; $G$ = granular cells. cells; $P=$ Purkinje cells; $G=$ granular cells.

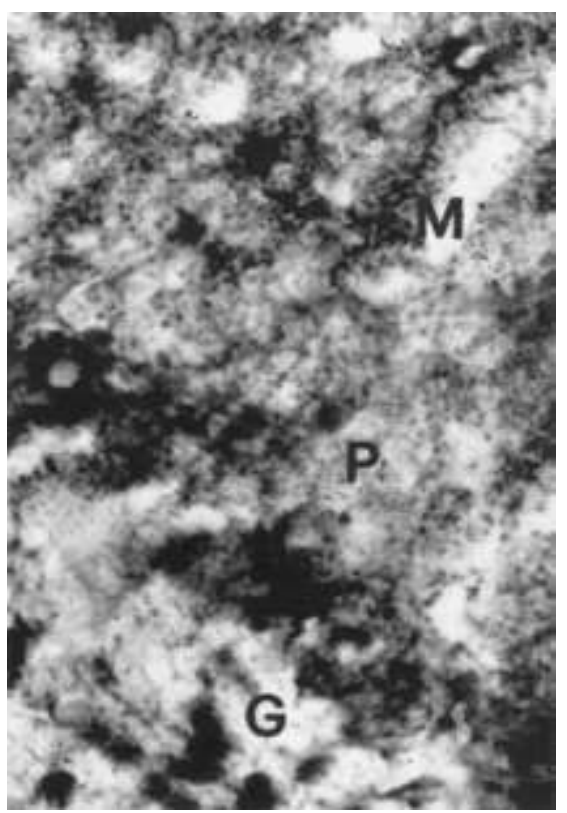

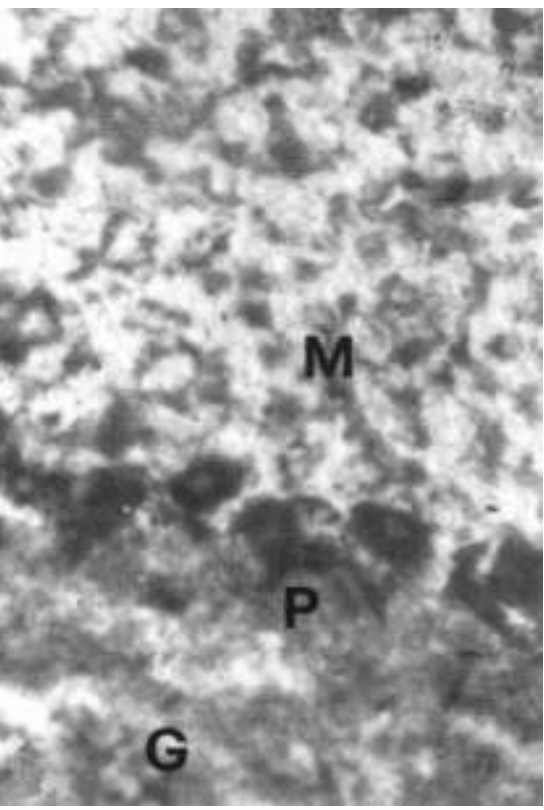

Figure 3. MAO-A activity in an young rat cerebellar cortex in presence of the inhibitor deprenyl $\left(10^{-7} \mathrm{M}\right)$ (magnification 100). A moderate MAO-A positive reaction is noticeable (deprenyl inhibits MAO-B) in the three cerebellar cortex layers. MAO activity is localized inside the cytoplasm of the nervous cells. $M=$ molecular cells; $P=$ Purkinje cells; $G$ = granular cells.

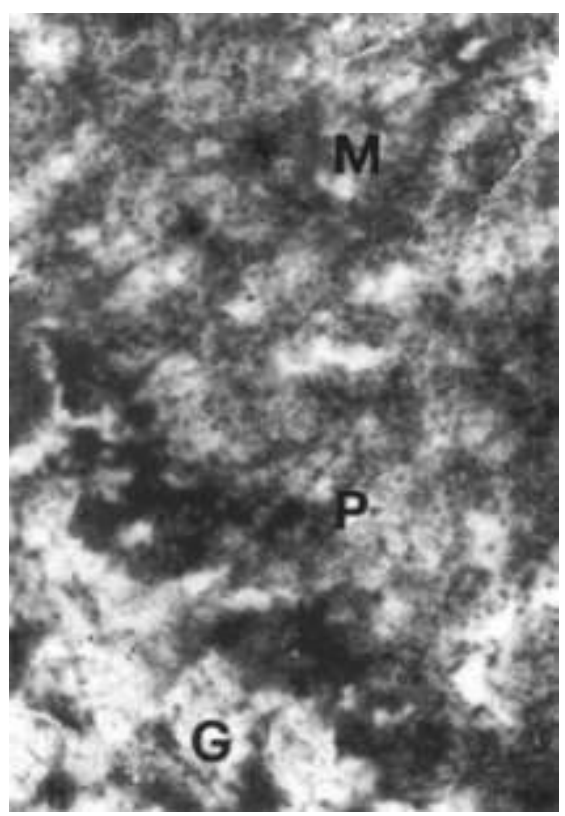

Figure 6. MAO-B activity in an old rat cerebellar cortex, as in Figure 5 (magnification 250). MAO levels are higher then these of Figure 5. Granular cells, however, show a less positive reaction. $M=$ molecular cells; $P=$ Purkinje cells; $G=$ granular cells. (the whole sample appears dark and there- (clorgyline inhibits MAO-A, about $70 \%$ of fore more positive after the reaction). $M=$ the whole reaction, as demonstrated by molecular cells; $P=$ Purkinje cells; $G=Q A I)$ is noticeable in the cells of the three granular cells. layers of the cerebellar cortex. $M=$ molecular cells; $P=$ Purkinje cells; $G=$ granular cells. 
noticeable.

Figures 3 and 4 must also be compared. They demonstrate the MAO-A staining (i.e. the staining obtainable with inhibitor deprenyl, used in this reaction, which inhibits $\mathrm{MAO}-\mathrm{B}$ and stains only MA0-A). In this case too, enzymatic staining is present in all three kinds of fundamental neurons of the cerebellar cortex.

Figures 5-6 must be compared because they concern the samples of young (Figure 5) or old (Figure 6) rat cerebellar cortex stained by using the specific MAO-A inhibitor clorgyline that points out only MAO-B enzymatic staining We must consider that while, in the heart, clorgyline inhibits all MAO staining (our unpublished results), in the cerebellum it inhibits only $30 \%$ of staining, as demonstrated by QAI. This finding makes it possible to say that in the cerebellum around $70 \%$ of MAO staining is not inhibited by clorgyline and, therefore, it is either MAO-B or MAO-C. Table 1 shows the morphological quantitative results of MAOs in the different cells of cerebellar cortex of young and old rats in comparison with biochemical results on the same samples reported in Table 2. Table 3 shows the biochemical data on the assay of MAO-B obtained by means of the use of the inhibitor clorgyline that inhibits about $30 \%$ of the total enzymatic activity.

\section{Discussion}

Considering the results of our experimental procedures, we can affirm that MAO levels in the cerebellar cortex of rats increase with age and that enzymatic staining is increased in all neurons (except for the neurons of the glomerular layer). The increase of enzymatic staining shows a close correlation with the progression of age and the evidences of neuro-degenerative and/or senile alterations. Our results demonstrate that in rat cerebellar cortex there is a relevant MAO staining in the Purkinje cells and in the cells of the molecular layers. In old rat cerebellar cortex MAO staining is more intense than that observed in young rats. However, in the granular layer of old rat cerebellum MAO staining decreases with aging, while in the Purkinje cells and in the molecular layer MAO staining strongly increases with aging.

It is well-known that the MAOs are neuronal enzymes able to degrade the biogenic amines (catecholamines) which have the function of neurotransmitters. Inside the presynaptic vesicles, the neurotransmitters are protected against the action of the intraneuronal enzymes, including the MAO. However, when they are released by the presynaptic vesicles, they can be metabolised by the intra-and extraneuronal enzymes.

In conclusion, our results demonstrate that in the cerebellum, all subgroups of MAO are present. In fact, in the cerebellum the use of the inhibitor clorgyline provokes only a decrease, not a disappearance, of the MAO staining, whereas in the heart (our unpublished results) the same inhibitor causes the complete disappearance of the staining.

Cerebellar MAOs play an important role in the biogenic amines metabolism (Blasko 1974). The biogenic amines are the catecholamine which, after being released in the catecholaminergic synapses, may be toxic for the surrounding structures and therefore must be rapidly either reuptaken or metabolised (Friedgen et al. 1996). Further studies are necessary to clarify the role of the single fractions of MAO in the metabolism and in the functions of young and old rat cerebellar cortex.

\section{References}

Beisenherz G. In: Colowick SP, Kaplan NO, eds. Methods in Enzymology. Vol. I, pag. 287, Academic Press: New York; 1955.

Blaschko H. The natural history of amine oxidase. Rev Physiol Biochem Pharmacol 1974;70:112-56.

Brus R. Activity of some enzymes which synthesize and metabolise catecholamines in the brain and peripheral organs in developing rats. Arch Immunol Ther Exper 1975;23:449-57.

Cao Danh H, Strolin M, Benedetti Dostert P, Mousset A. Age-related changes in benzylamine oxidase activity in rat tissues. J Pharm Pharmacol 1984;36:592-6.

Castino M, Roletto E. Statistica Applicata. Edizioni Piccin, Padua 1992.

Esiri MN, Nagy Z, Smith MZ, Barneston L, Smith AD. Cerebrovascular disease and threshold dementia in the early stage of Alzheimer's disease. Lancet 1996;354:919-20.

Fowler CJ, Oreland L, Callingham BA. The acetylenic monoamine-oxidase inhibitors clorgyline, deprenyl, pargiline and J-508: their properties and applications. J Pharm Pharmacol 1981;33:341-7.

Fowler CJ, Wiberg A, Oreland L, Marcusson J, Winblad B. The effect of age on the activity and molecular properties of human brain monoamineoxidase. J Neural Transm 1980;49:1-20.

Friedgen B, Wolfel R, Russ H, Schomig E, Graefe $\mathrm{KH}$. The role of extraneuronal amine transport systems for the removal of extracellular catecholamines in the rabbit. Naunyn Schmiedebergs Arch Pharmacol 1996:354:275-86.

Handbook of Methods. Quantimet 500 Leica, Microsystems imaging Solutions. Ed. Clifton Road, Cambridge, U.K.

Hoffman A, Ott A, Breteler MN. Atherosclerosis, apolipoprotein and prevalence of dementia and Alzheimer disease in the Rotterdam study. Lance 1997;349:151-4.

Johnston JP. Some observation upon a new inhibitor of monoamine oxidase in brain tissue. Biochem Pharmacol 1968;17:1285-97.

Knoll J, Magyar K. Some puzzling pharmacological effects of monoamine oxidase inhibitors. Biochem Psychopharmacol 1972;5: 393-408.

Lai FM, Berkowitz B, Spector S. Influence of age on brain vascular and cardiovascular monoamine oxidase activity in the rat. Life Sci 
F. M. Tranquilli et al.

1978;22:2051-6.

Lowry $\mathrm{OH}$, Rosebrough NJ, Farr AL, Randall J. Protein measurement with the folin phenol reagent. J Biol Chem 1951;193: 265-75.

Moody DM, Brown WR, Challa VR, Ghazi-Birry HS, Reboussin DM. Cerebral microvascular alterations in aging, leukariosis and Alzheimer's disease. Ann NY Acad Sci 1997;826:103-16.

Owen $F$, Crow TJ, Frith CD, Johnson JA, Johnstone EC, Lofthouse R, et al. Selective decreases in MAO-B activity in post-mortem brains from schizophrenic patients with type II syndrome. Br J Psychiatr 1987; 151:514-9.

Prange AJ Jr, White JE, Lipton MA. Influence of age on monoamine oxidase and Comt in rat tissues. Life Sc 1967;6:581-6.

Saura J, Luque JM, Cesura AM, Da Prada M, Chan-Palay V, Huber G, et al. Increased monoamineoxidase $B$ activity in plaque-associated astrocytes of Alzheimer brains revealed by quantitative enzyme autoradiography. Neuroscience 1994a;62:15-30.

Saura J, Richards JG, Maly N. Differential age-related changes of MAO-A and MAO-B in mouse brain and peripheral organs. Neurobiol Aging 1994b;15:399-408.

Serio A. Appunti delle lezioni di Statistica Sanitaria. Edizioni Kappa; 1986, Roma.

Studer A, Baumgartner HR, Reber K. Histochemical evidence of monoamine oxidase activity in rats of different ages. Histochemie 1964; 4:43-7.
Thomas T, McLendon C, Thomas G. L-Deprenyl protects vascular endothelium from amyloid-b toxicity and stimulates production of nitric oxide. In: Alzheimer disease and related disorders. J. Wiley \& Sons Ltd., p. 493-500.

Thomas T, McLendon C, Thomas G. L-Deprenyl: nitric oxide production and dilation of cerebral blood vessels. Neuroreport 1998;9:2595600.

Thomas T, Rhodin JAG, Sutton ET. Estrogen protects peripheral and cerebral blood vessels from toxicity of Alzheimer's peptide amyloid$b$ and inflammatory reaction. J Submicrosc Cytol Pathol 2000;1:32-41.

Thomas T. Monoamine oxidase-B inhibitors in the treatment of Alzheimer's disease. Neurobiol Aging 2000;21:343-8.

Tipton KF, Fowler CJ, McCrodden JM, Strolin Benedetti M. The enzyme-activated irreversible inhibition of type-B Mao by compound [MD 780236] and the enzyme-catalised oxidation of this compound as competing reactions. Biochem J 1983;209:235-42.

Tipton KF, Houslay MD, Mantle TJ. The nature and location of the multiple forms of monoamine oxidase, in Mono-amine oxidase and its inhibition. CIBA Foundation Symposium 1976;39:5-25.

Uchida $E$, Koelle GB. Histochemical investigation of criteria for the distinction between monoamine oxidase $A$ and $B$ in various species. $\mathrm{J}$ Histochem Cytochem 1984;32:667-73. 